\title{
Avaliação do Risco de Parto Prematuro através da Autopalpação e da Monitorização Computadorizada da Contração Uterina
}

Autor: Carla Muniz Pinto de Carvalho da Silva Cesar

Orientador: Prof. Dr. Eduardo de Souza

Tese de Mestrado apresentada à Escola Paulista de Medicina - Universidade Federal de São Paulo em 9/8/1999.

Objetivo: avaliar o risco de parto prematuro por meio da autopalpação e da monitorização computadorizada da contração uterina; verificar a influência de características maternas na autopalpação.

Metodologia: estudaram-se, prospectivamente 93 gestantes com antecedente de prematuridade espontânea. Realizou-se monitorização da contração uterina por cardiotocografia computadorizada e educação para autopalpação da contração em domicílio e em ambiente hospitalar. Os exames foram realizados da 24 à $36^{a}$ semana, durante uma hora. A curva ROC determinou o melhor ponto de corte para predição do parto antes de 34 e 37 semanas.

Resultados: a incidência de parto prematuro foi de $37,6 \%$. A autopalpação domiciliar revelou sensibilidade de $53 \%$ e $51 \%$, especificidade de $47 \%$ e $47 \%$, valor preditivo positivo (VPP) de 16 e $37 \%$ e valor preditivo negativo (VPN) de 84 e 61\%, para predição antes de 34 e 37 semanas, respectivamente. A monitorização externa apresentou sensibilidade de $67 \%$ e $69 \%$, especificidade de $29,5 \%$ e $29 \%$, VPP de $15 \%$ e $37 \%$ e VPN de $82 \%$ e $61 \%$ para 34 e 37 semanas respectivamente. A autopalpação hospitalar apresentou sensibilidade de $87 \%$ e $74 \%$, especificidade de $35 \%$ e $34,5 \%$, VPP de $20 \%$ e $41 \%$ e VPN de $93 \%$ e $69 \%$ para 34 e 37 semanas, respectivamente.

Conclusões: a monitorização e autopalpação da contração uterina são fatores importantes a considerar devido ao seu elevado VPN; a autopalpação domiciliar apresentou melhores resultados em relação a realizada em domicílio e não foi influenciada pela idade, índice de massa corpórea, escolaridade e renda familiar.

Palavras-chave: Prematuridade. Trabalho de parto prematuro. Contração uterina

\section{Bacteriúria após Drenagem Vesical no Pós-Operatório de Cirurgias Ginecológicas Vaginais: Comparação entre as Vias Transuretral e Suprapúbica}

Autor: Fernando Mesquita de Almeida

Orientador: Prof. Dr. Georthon Rodrigues Philocreon

Dissertação apresentada ao Instituto de Patologia Tropical e Saúde Pública da Universidade Federal de Goiás para obtenção do título de Mestre em Medicina Tropical, em 20/8/1999.

A maioria das infecções nosocomiais do trato urinário está relacionada ao cateterismo da bexiga. Muitas pacientes submetidas a cirurgias ginecológicas pela via vaginal necessitam de sondagem da bexiga para a drenagem de urina no pós-operatório. Na literatura atual existem poucas publicações comparando as vias transuretral e suprapúbica no que se refere à incidência de bacteriúria. O objetivo do presente estudo foi comparar a drenagem vesical por estas vias, no pósoperatório de cirurgias ginecológicas vaginais, no que se refere à ocorrência de bacteriúria. De forma prospectiva, foram estudadas 129 mulheres submetidas a cirurgias ginecológicas vaginais. Dessas, 63 pacientes foram sondadas pela via suprapúbica e 66 apenas pela via transuretral. Todas as pacientes apresentavam urocultura negativa no pré-operatório e tiveram amostras de urina analisadas também no pós-operatório. O diagnóstico de "bacteriúria significativa" foi firmado pela presença de 100000 colônias de bactérias por mililitro de urina ou mais. As amostras de urina foram colhidas do jato médio da primeira micção do dia. Trinta e nove das 129 pacientes estudadas (30,23\%) tiveram bacteriúria significativa no pós-operatório. Nove das 63 pacientes $(14,28 \%)$ sondadas pela via suprapúbica e trinta das 66 pacientes $(45,46 \%)$ sondadas pela via transuretral apresentaram bacteriúria significativa na amostra de urina colhida após a retirada definitiva da sonda. Esta diferença foi altamente significante (teste qui-quadrado, $\mathrm{p}<0,01$ ). A Escherichia coli foi o microrganismo encontrado no maior número de casos com uroculturas significativas. Não houve complicações graves durante o uso das sondas vesicais tanto pela via suprapúbica quanto transuretral.

Palavras-chave: Bacteriúria. Cirurgia: complicações. Sondagem vesical. 